\title{
Partisipasi Orang Kristen dalam Perpolitikan di Indonesia
}

\author{
James
}

\author{
Fakultas Hukum, Universitas Medan Area, Indonesia
}

Diterima Agustus 2016; Disetujui Oktober 2016; Dipublikasikan Desember 2016

\begin{abstract}
Abstrak
Umat Kristen adalah bagian dari Negara dan berada di tengah-tengah Negara yang pasti memiliki sistem politik. Banyak umat Kristen merasa enggan apabila berbicara tentang politik, apalagi diminta ambil bagian dalam perpolitikan. Mungkin faktor yang membuat sikap demikian adalah kurangnya pemahaman tentang politik, dan kurangnta pemahaman tentang tugas dan tanggung jawab mereka sebagai orang percaya dan juga sekaligus sebagai seorang warga negara. Dari sudut firman Allah sendiri banyak hal yang mengajarkan kita untuk ambil bagian dalam Kesejahteraan dimana kita tinggal (Yeremia 29:7). Secara inflisit sebenarnya mengajak kita agar ambil bagian berpartisipasi dalam perpolitikan dimana kita berada, sehingga kita bisa menjadi garam dan terang dalam politik tersebut.
\end{abstract}

Kata Kunci: Politik; Partisipasi; Garam dan Terang; Umat Kristen

\begin{abstract}
Christian Community is well acknowledged as a part in nation and do live among the people under state with certain owned political system. There are many people in community be hesitated in political concern even asking be actively to take part in political activities. It is probably the factor causes as one got alike behave due to shortage knowledge about the political itself, also due to shortage knowledge about the duties and responsibilities that one should take. As a believer and at once as a lay people where one be living, in God's words there are many things guide people that should take part in order to improve people welfare wherever one be living (Jeremiah 29:7). Implicitly, God's words encourage us to take part and be actively participated in political concerned where we live in town, it make us to show how can be someone become a shine and salt in the political concerned.
\end{abstract}

Keywords : Politics; Participation; Shine And Salt; Christian.

How to Cite: James, (2016). Partisipasi Orang Kristen dalam Perpolitikan di Indonesia, Anthropos: Jurnal Antropologi Sosial dan Budaya, 2 (2) (2016): 187-191.

\begin{tabular}{lr}
\hline *Corresponding author: & p-ISSN 2460-4585 \\
E-mail: umajamesuma@yahoo.com & e-ISSN 2460-4593
\end{tabular}




\section{PENDAHULUAN}

Ada dua sisi pandnagan umum tentang politik. Pandangan pertama, adalah memandang politik itu dari sudut negative. Pandangan ini menganggap politik itu adalah permainan kotor, politik mencari kekuasaan, politik itu adalah kawasan yang bebas kejujuran. Dalam politik tidak ada musuh yang abadi dan tidak ada teman yang abadi, tetapi kepentingan yang abadi.

Pandangan-pandangan di atas membuat sebagian orang bersikap negative terhadap politik, termasuk didalamnya orang-orang Kristen, sehingga ada orang Kristen yang tidak mau terlibat dalam politik bahkan beranggapan politik adalah sarang dari dosa, tetapi sebaliknya ada orang yang berpetualang dalam politik dengan memanfaatkan pandangan negatif ini untuk mencapai tujuan, dengan menghalalkan segaala cara.

Pandangan kedua adalah memandang politik sebagai suatu seni, politik itu bentuk pengabdian pada bangsa dan negara dan politik itu bertujuan untuk mensejahterakan warga negara. Maka dengan pandangan ini, banyak orang berjuang dalam dunia, banyak orang Kristen yang mengklaim bahwa mereka aktif dalam politik adalah sebagai panggilan atau amanah pengabdian.

Maksud dan tujuan pembahasan ini adalah agar Kristen memperoleh pemahaman yang mendalam, dan komprehensip tentang berpolitik dan khususnya bagaimana orang Kristen berpartisipasi dalam politik yang benar.

\section{PEMBAHASAN}

Menurut ahli politik, pengertian politik secara hakiki adalah segala rencana, usaha dan tindakan/kegiatan untuk memelihara dan mengelola negara dan tujuannya adalah untuk memperbaiki dan meningkatkan kesejahteraan warga negara. Kita mengetahui bahwa yang disebut negara terdiri dari tiga unsur yaitu wilayah rakyat dan pemerintah. Segala sesuatu yang berkaitan dengan wilayah, rakyat dan pemerintah adalah bagian dari negara.

Berdasarkan pengertian di atas maka jika kita berpartisipasi dalam politik. Jalan yang dapat dipakai bukan hanya jalur pemerintah atau kuasa, tetapi juga jalur kewilayahan atau jalur rakyat. Melakukan kegiatan dan pemikiran tentang soal-soal wilayah dan soal-soal rakyat misalnya : tentang pengembangan wilayah kesejahteraan, keadilan, keamanan, pendidikan adalah juga termasuk dalam lingkup politik.

Namun dalam memberikan darma baktinya itu, orang Kristen sebagai warga negara yang baik harus sadar diri sebagai apa posisi dan perannya dalam negara dan masyarakat orang Kristen tidak etis melkaukan darma baktinya jika tidak sesuai dengan posisi dan perannya dalam negara dan masyarakat. Orang Kristen juga harus menghargai posisi dan peran warga negara yang lain, atau harus menghargai posisi dan peran aparatur negara, apakah itu unsur eksekutif, legislatif, yudikatif.

Pemerintah politik berbeda dengan pelayanan kristiani. Yakobus an Yohanes pernah meminta jabatan khusus kepada Yesus yaitu: kedudukan disebelah kanan dan disebelah kiri Yesus (Mark 10:37), tetapi Yesus mengatakan : "kamu tidak tahu apa yang kamu minta .... (ayat 38).

Rupanya kedua murid ini mengira kerajaan Yesus adalah seperti kerajaan dunia (politis). Kemudian Yesus berkata kepada seluruh murid, kamu tahu bahwa mereka yang disebut pemerintah bangsabangsa pemerintah rakyatnya dengan tangan besi dan pembesar-pembesarnya menjalankan kuasanya dengan keras atas 
mereka. Tidak demikian diantara kamu. Barang siapa ingin menjadi besar diantara kamu, hendaklah ia menjadi pelayanmu .... Karena anak manusia juga datang bukan untuk dilayani, melainkan untuk melayani dan memberikan nyawaNya menjadi tebusan bagi banyak orang (Mark 10:4245).

Dengan penjelasan di atas, ditegaskan bahwa pelayanan kristiani berbeda dengan pemerintahan politis. Yesus datang ke dunia membawa pola dan suasana baru tentang jabatan, kuasa dan pelayanan. Jabatan dan kuasa dalam pelayanan kristiani adalah berdasar pada pengabdian dan pengorbanan bagi banyak orang. Sedangkan pada politik kekuatan dan kekuasaan menjadi pola kepemimpinan yang sah.

Pada masa Yesus, ada kelompokkelompok masyarakat Yahudi yang mencoba mempertentangkan iman dengan politik "beberapa orang Farisi dan Herodian bertanya kepada Yesus", Apakah diperbolehkan membayar pajak kepada Kaisar atau tidak? .... Haruskah kami bayar pajak atau tidak? Kemudian Dia menjawab dengan tegas, Berilah kepada Kaisar apa yang wajib kamu berikan kepada Kaisar apa yang wajib kamu berikan kepada Kaisar, dan kepada Allah yang apa yang wajib kamu berikan kepada Allah (Markus 12:13-17). Dengan penyataan ini berarti orang Kristen tidak anti kepada pemerintahan politik malahan dalam Kitab Roma 13:1-7 ditegaskan lagi "tiap-tiap orang Kristen harus takluk kepaa pemerintah yang diatasnya, sebab tidak ada pemerintah yang tidak berasal dari Allah dan pemerintah -pemerintah yang ada dditetapkan oleh Allah.

Firman Allah memberi tanggung jawab kepada orang Kristen agar menjadi garam dan terang dunia (Matius 5:13-16).
Dunia yang dimaksud adalah juga meliputi dunia politik, tetapi bagaimana orang Kristen menjadi garam dan terang dalam dunia politik?

Dalam praktek berpolitik tentu tidak lepas dari kekurangan dan penyimpangan. Malahan ada orang-orang politik dengan sadar melakukan trik-trik politik yang bertentangan dengan kebenaran, dan keadilan. Oleh karena itu jika orang Kristen berpartisipasi dalam dunia politik, maka mereka harus berani menjadi garam dan terang. Menjadia garam dalam dunia politik berarti memberikan kualitas yang lebih baik dalam sikap dan perilaku berpolitik. Orang Kristen harus berani memberi contoh dan kritik yang sehat dalam berpolitik berarti orang Kristen terpanggil "menciptakan" nuansa berpolitik jujur tetapi cerdas.

Bersaksi, bersekutu dan melayani adalah tiga bentuk partisipasi hal disebut Tri Tugas orang Kristen dalam dunia. Bersaksi dalam politik artinya memberi sikap, buah pikiran dan tindakan yang tujuannya menegakkan kebenaran dan keadilan. Firman Allah berkata "Beritakanlah firman, siap sedialah, baik atau tidak baik waktunya, nyatakanlah apa yang salah, tegorlah dan nasehatilah dengan segala kesabaran dan pengajaran (II Timotius 4:2). Jika dalam praktekpraktek pengolahan negara terjadi hal-hal yang tidak sesuai dengan kebenaran dan keadilan maka orang Kristen dapat memberikan masukan berupa saran, kritik ataupun protes.

Bersekutu dalam politik berarti bahwa sebagai garam dan terang orang Kristen harus hadir dalam dunia, seperti garam, orang Kristen harus melarut dalam dunia politik agar efektif dalam memberi nuansa kristiani terhadap perilaku-perilaku berpolitik. Bersekutu dalam politik tidak 
harus memasuki partai politik atau melakukan kegiatan-kegiatan politik praktis, tetapi bersekutu dalam politik artinya membuat diri inklusif dan perkembangan politik. Mengikuti perkembangan dan dinamika politik secara peka dan tanggap. Bersekutu dalam politik boleh dengan cara mengikuti trend politik yang sedang terjadi, dan mencoba memahami apa makna dari peristiwa yang terjadi itu. Orang Kristen juga tidak boleh buta politik tetapi sangat berguna jika orang Kristen dapat mengantisipasi kecenderungan-kecenderungan politis.

Melayani dalam politik artinya memberi diri untuk orang lain, sehingga orang lain, dapat memahami kecenderungan politik atau tidak terjebak dalam permainan politik. Orang Kristen harus mampu memberi pelayanan kepada orang-orang miskin, orang-orang tawanan, orang-orang tertindas, dan orang-orang yang menjadi korban permainan politik, tetapi dalam pelayanan itu, orang Kristen juga harus menghindaari cara-cara dan bentuk-bentuk kekerasan. Orang Kristen melayani dalam politik berarti orang Kristen memberi sesuatu yang berguna untuk pengembangan dan kewajiban etika berpolitik yang santun dan bermartabat.

Partisipasi kita sebagai orang Kristen dalam politik, tidak hanya pada aspekaspek duniawi atau jasmani saja melainkan roh kita juga ikut terlibat dalam dinamika politik. Firman Allah juga mengajarkan kita agar kita senantiasa mendo'akan negara (Yeremia 29:7) dan mendo'akan para penguasa (I Timotius 2:2). Mendoakan negara dan para penguasa bukan berarti kita memfasilitasi doa-doa kita, tetapi mendoakan penguasa dan negara berarti bathin dan roh kita juga ikut menggumuli persoalan dan perkembangan politik.
Ada tiga bentuk aktivitas politik yang dapat diperankan orang Kristen, yaitu : 1) Pengamat politik, 2) Anggota Partai politik kebangsaan, 3) Anggota partai politik Kristen

Menjadi pengamat politik ialah berperan untuk pencerahan dan pencerdasan berpolitik, berusaha memberikan pemikiran-pemikiran dan abalisis politik yang ilmiah, jujur dan konsisten.

Sedangkan tugas partai politik, terikat dengan plot form, visi dan misi partai politik yang diikuti. Partai politik apapun yang diikuti oleh orang Kristen, hal yang tidak boleh dilupakan ialah : 1) Politikus Kristen harus menjadi garam dan terang, 2) Politikus Kristen harus pintar, tulis dan waspada terhadap semua orang (Matius 10:16-17)

\section{KESIMPULAN}

Politik adalah segala rencana, usaha dan tindakan kegiatan untuk memlihara dan mengelola negara yang tujuannya untuk mewujudkan kesejahteraan rakyat. Politik tidak identik dengan pelayanan Kristen, tetapi pelayanan Kristen juga meliputi aspek politik: iman Kristen memahami pemerintahan politik dari dua sisi, yaitu politik yang bersifat negatif, yaitu yang memanfaatkan politik untuk hal-hal yang tidak baik, dan politik yang bersifat positif dimana politik itu digunakan sebagai sarana untuk melakukan hal-hal yang baik dan mulia. Sebagai orang Kristen tentu haruslah melakukan politik itu untuk halhal yang baik dan mulia karena itu adalah wujud nyata sebagai garam dan terang dunia. Tentu hal ini dapat diwujudkan dengan ambil bagian berpartisipasi dalam perpolitikan. 


\section{DAFTAR PUSTAKA}

Stott, John, Isu-Isu Global, Jakarta, 1984

Broawrlee, Tugas Manusia dalam dunia Milik Tuhan, Jakarta, 2004

Silitonga, SAM, Nilai-Nilai Kependidikan dari Yesus, Medan, 2000
Puspita, H., Sosiologi Agama Yogyakarta, 1990

Tim Dosen Unimed, PAK Untuk Perguruan Tinggi, Medan, 2007

Mulder, D.C., Iman dan Ilmu Pengetahuan, Jakarta, 1983 